\section{'Sujeong': A Green Seedless Table Grape Cultivar}

\author{
Jae-Yun Heo \\ Agriculture and Life Sciences Research Institute, Kangwon National \\ University, Chuncheon 24341, Korea
}

Sung-Min Park ${ }^{1}$

Department of Horticulture, Kangwon National University, Chuncheon 24341, Korea

Additional index words. pomology, triploid, Vitis species

Korean markets have recently shown a strong demand for grapes with large-sized seedless fruits (Heo and Park, 2015), and several attempts to introduce world-class seedless grape cultivars, such as Thompson Seedless and Crimson Seedless, have been made. However, they are not adapted to Korea's climate and are not recommended for commercial planting in Korea. Therefore, seedless grapes have been produced in Korea by applying gibberellins $\left(\mathrm{GA}_{3}\right)$ to tetraploid seeded grape cultivars such as Kyoho. Producing seedless fruits from seeded grape cultivars generally requires two $\mathrm{GA}_{3}$ applications and cluster thinning treatments before and after blooming (Lee et al., 2013), which increase the production costs. Furthermore, fruit characteristics can be differentially expressed depending on what time the $\mathrm{GA}_{3}$ applications occur (Abu-Zahra, 2013), and it can be difficult for farmers to produce seedless grapes with uniform fruit characteristics. Therefore, the development of seedless grape varieties that can be easily produced has been regarded as an important aim of the grape breeding program in Korea.

Triploid grapes have low pollen fertility due to their unbalanced chromosome sets (Yamashita et al., 1998), and previous research has suggested that it may be possible to produce large-sized seedless fruits using one $\mathrm{GA}_{3}$ application (Heo and Park, 2016). However, it has been reported that many triploid grape cultivars require two $\mathrm{GA}_{3}$ applications to produce commercially valuable fruits (Wakana et al., 2008). Therefore, evaluating the influence of one $\mathrm{GA}_{3}$ application on fruit quality and size in a large number of triploid progenies derived from various crosses is critical when attempting to breed labor-saving triploid grapes. We made several interploid crosses using 12 diploid and seven tetraploid grape cultivars, and obtained a total of 270 triploid seedlings (Heo et al., 2007). After various screening

Received for publication 2 Nov. 2016. Accepted for publication 24 Dec. 2016.

We are grateful to the Kangwon National University for providing project funding (D1000805-01-01).

${ }^{1}$ Corresponding author. E-mail: parksm@kangwon. ac.kr. tests, we finally developed a labor-saving triploid seedless grape called 'Sujeong'.

\section{Origin}

'Sujeong' is a cross between 'Kyoho' and 'Thompson Seedless' (Fig. 1). This cross was made in 2000 at Kangwon National University (KNU) farm, which is located in Chuncheon, Republic of Korea. The original plant was planted at KNU farm in 2001 and was propagated in 2002 at Bibong orchard, Hwaseong. The vine and fruit characteristics of 'Sujeong' were compared with a triploid grape cultivar King Dela for 2 years in Chuncheon (2004 and 2005) and Hwaseong (2005 and 2006). 'Sujeong' was finally selected in 2006, due to its superior agricultural performance, and was sent to the Korea Seed \& Variety Service (KSVS) in Iksan for agricultural performance evaluations. Sujeong became a protected grape cultivar in Korea after these evaluations had been completed.

\section{Description and Performance}

'Sujeong' is as vigorous as other triploid grape cultivars (Heo and Park, 2015; Wakana et al., 2008), and has a shoot growth pattern that is similar to the one reported by Borghezan et al. (2012). The shoot grows very vigorously just before flowering, but shoot growth tends to decline as the focus of the vine shifts toward fruit production. 'Sujeong' vines are moderately winter hardy. They tend to be less winter hardy than the American origin grape cultivars, and winter protection is required in regions having a cold climate.

'Sujeong' vines have relatively high disease resistance to powdery mildew (Erysiphe cichoracearum DC.) and gray mold (Botrytis cinerea Per.:Fr.), but show sensitivity to anthracnose (Elsinoe ampelina Shear) and downy mildew (Plasmopara viticola Berl. \& de Toni). Therefore, it is recommended that 'Sujeong' vines are cultivated under a rain shelter greenhouse to protect them from anthracnose and downy mildew damage. 'Sujeong' flowers are perfect, and 'Sujeong' pollen is highly sterile: none of the 3000 pollen grains from 'Sujeong' germinated on the agar medium (sucrose $20 \mathrm{~g} \cdot \mathrm{L}^{-1}$; agar $3 \mathrm{~g} \cdot \mathrm{L}^{-1}$ ) during the pollen germination test.

In the non-GA $\mathrm{G}_{3}$-treated flower clusters, fruit set occurred and resulted in the formation of small and seedless berries. The small berry formation results from stimulative parthenocarpy with highly sterile 'Sujeong' pollen. The mean weight of the berries was around $2 \mathrm{~g}$, and they had a green skin color at ripening. When the 'Sujeong' flower clusters were immersed once in a solution of $100 \mathrm{ppm}$ $\mathrm{GA}_{3}$ at full bloom, the berry weight and berry set from the treated flower clusters increased compared with the clusters that had not received the $\mathrm{GA}_{3}$ treatment. Although cluster volume becomes abundant and improves considerably after $\mathrm{GA}_{3}$ treatment, the berries were not susceptible to cracking from rainfall near or at maturity. Thus, thinning treatment is rarely required. However, the removal of some parts of the clusters during the full bloom period in this cultivar can be undertaken to produce bigger fruits. In addition, berry shattering, which leads to low marketability due to poor cluster appearance, does not happen. The cluster and berry shapes produced by 'Sujeong' are conical and elliptical, respectively, and the fruits have an attractive green color at maturation (Fig. 2). The average cluster and berry weight recorded at the two sites reached $436.1 \mathrm{~g}$ and $5.6 \mathrm{~g}$, respectively (Table 1). 'Sujeong' showed high flower bud differentiation, which led to a production average of $12.6 \mathrm{~kg} / \mathrm{vine}$. Its fruit productivity was much higher than that of 'King Dela', and was similar to that of other grape cultivars widely cultivated in Korea. 'Sujeong' fruit has a soft and juicy flesh texture, and the average total soluble solids (TSS) content and titratable acidity (TA) were $20.0 \%$ and $0.54 \%$, respectively. 'Sujeong' berries have a well-balanced TSS:TA ratio, which results in excellent fruit taste. In general, the cluster and berry characteristics in central Korea are similar to those in northern areas. 'Sujeong' is harvested in the last week of September and can be harvested around the same time as the Chuseok holiday. This is important because fruit prices tend to increase considerably during the Chuseok holiday in Korea, which means that cultivating 'Sujeong' can be very profitable.

'Sujeong' produces large-sized and highquality seedless fruits after a single $\mathrm{GA}_{3}$ application, and has the appropriate number of seedless fruits without cluster thinning.

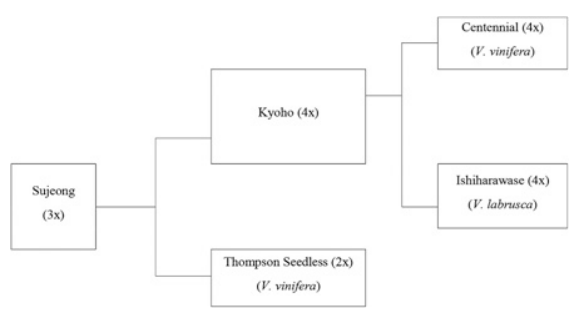

Fig. 1. Pedigree of triploid seedless grape 'Sujeong'. 
Table 1. Cluster and fruit characteristics in non- $\mathrm{GA}_{3}$ or $\mathrm{GA}_{3}$-treated 'Sujeong' and 'King Dela' grapes. ${ }^{\mathrm{z}}$

\begin{tabular}{|c|c|c|c|c|c|c|c|c|c|c|c|c|c|c|}
\hline \multirow[b]{2}{*}{ Cultivar } & \multirow[b]{2}{*}{ Region } & \multicolumn{3}{|c|}{ Non- $\mathrm{GA}_{3}$ treatment } & \multicolumn{10}{|c|}{$\mathrm{GA}_{3}$ treatment } \\
\hline & & $\begin{array}{l}\text { Cluster } \\
\text { wt }(g)^{y}\end{array}$ & $\begin{array}{l}\text { Berries per } \\
\text { cluster }^{\mathrm{y}}\end{array}$ & $\begin{array}{l}\text { Berry } \\
\text { wt }(g)^{y}\end{array}$ & $\begin{array}{c}\text { Harvest } \\
\text { date }\end{array}$ & $\begin{array}{l}\text { Clusters } \\
\text { per vine }\end{array}$ & $\begin{array}{c}\text { Yield } \\
(\mathrm{kg} / \text { vine })^{\mathrm{x}}\end{array}$ & $\begin{array}{c}\text { Expected } \\
\text { yield }\left(\mathrm{t} \cdot \mathrm{ha}^{-1}\right)^{\mathrm{w}}\end{array}$ & $\begin{array}{l}\text { Cluster } \\
\text { wt }(g)^{y}\end{array}$ & $\begin{array}{l}\text { Berries per } \\
\text { cluster }^{y}\end{array}$ & $\begin{array}{c}\text { Berry } \\
\text { wt }(g)^{y}\end{array}$ & $\begin{array}{l}\text { TSS } \\
(\%)^{\mathrm{v}}\end{array}$ & $\begin{array}{l}\text { TA } \\
(\%)^{v}\end{array}$ & TSS/TA \\
\hline \multirow[t]{2}{*}{ Sujeong } & Chuncheon & 81.2 & 41.6 & 1.9 & 29 Sept. & 29.3 & 12.5 & 13.9 & 427.6 & 75.0 & 5.7 & 19.8 & 0.55 & 36.0 \\
\hline & Average & 82.9 & 41.9 & 2.0 & - & 29.0 & 12.6 & 14.0 & 436.1 & 78.7 & 5.6 & 20.0 & 0.54 & 36.9 \\
\hline \multirow[t]{3}{*}{ King Dela } & Chuncheon & 68.4 & 38.5 & 1.7 & 1 Sept. & 32.7 & 7.6 & 8.4 & 233.4 & 75.2 & 3.1 & 18.1 & 0.51 & 35.4 \\
\hline & Hwaseong & 73.8 & 40.9 & 1.8 & 28 Aug. & 34.3 & 8.9 & 9.9 & 261.9 & 77.0 & 3.4 & 17.7 & 0.54 & 32.7 \\
\hline & Average & 71.1 & 39.7 & 1.8 & - & 33.5 & 8.3 & 9.2 & 247.7 & 76.1 & 3.3 & 17.9 & 0.53 & 34.1 \\
\hline
\end{tabular}

$\mathrm{GA}_{3}=$ gibberellins; TSS $=$ total soluble solids; TA $=$ titratable acidity.

${ }^{z}$ Cluster and fruit characteristics of 'Sujeong' and 'King Dela' were investigated from 2004 to 2005 at Chuncheon and from 2005 to 2006 at Hwaseong, Republic of Korea. 'Sujeong' and 'King Dela' were grown under rain shelter greenhouse.

${ }^{\mathrm{y}}$ Means of cluster weight and berries per cluster were measured from 10 clusters taken from each of three vines $(\mathrm{n}=30)$.

${ }^{x}$ Means of clusters per vine and yield were calculated from the observation of three vines of each cultivar $(n=3)$.

${ }^{\text {w}}$ Spacing $3 \mathrm{~m} \times 3 \mathrm{~m}$ (1111 vines/ha).

${ }^{\mathrm{v}}$ Average TSS, TA, and TSS/TA were measured from 300 berries.

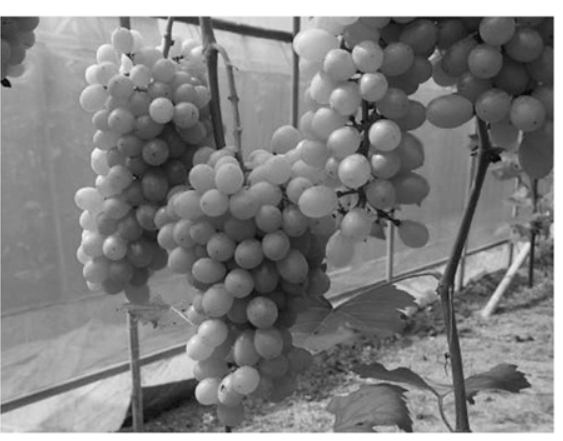

Fig. 2. Cluster of 'Sujeong' grape.

These advantages can help Korean farmers keep labor costs down when producing seedless grapes. Therefore, the introduction of the Sujeong cultivar is expected to contribute to the diversification of Korean grape cultivars and will improve the competitiveness of the Korean grape industry.

\section{Availability}

'Sujeong' is a patented Korean cultivar from KSVS and is owned by KNU. Requests for cuttings for research purposes may be addressed to Sung-Min Park (parksm@kangwon.ac.kr).

\section{Literature Cited}

Abu-Zahra, T.R. 2013. Effect of plant hormones application methods on fruit quality of 'Superior Seedless' grape. Biosci. Biotech. Res. Asia. 10:527-531.

Borghezan, M., O. Gavioli, H.J. Vieira, and A.L. da Silva. 2012. Shoot growth of Merlot and Cabernet Sauvignon grapevine varieties. Pesqui. Agropecu. Bras. 47:200-207.

Heo, J.Y., K.S. Park, H.K. Yun, and S.M. Park. 2007. Degree of abortion and germination percentage in seeds derived from interploid crosses between diploid and tetraploid grape cultivars. Hort. Environ. Biotechnol. 48:115121.

Heo, J.Y. and S.M. Park. 2015. Breeding of a new triploid seedless table grape cultivar 'Paradise'. J. Amer. Pomol. Soc. 69:170-172.

Heo, J.Y. and S.M. Park. 2016. Variation in fruit characteristics of $3 \mathrm{x}$ progenies obtained from a cross between $4 \mathrm{x}$ and $2 \mathrm{x}$ grape cultivars. Korean J. Hort. Sci. Technol. 34:761-770.

Lee, B.H.N., Y.H. Kwon, Y.S. Park, and H.S. Park. 2013. Effect of $\mathrm{GA}_{3}$ and thidiazuron on seedlessness and fruit quality of 'Kyoho' grapes. Korean J. Hort. Sci. Technol. 31:135-140.

Wakana, A., I. Fukudome, N. Hanada, M. Hiramatsu, K. Sakai, and K. Kajiwara. 2008. 'Bei-kei', a new triploid seedless grape cultivar derived from a 'Muscat Bailey A' $\times$ 'Kyoho' cross. J. Fac. Agr. Kyushu Univ. 53:423-427.

Yamashita, H., I. Shigehara, and T. Hanuda. 1998. Production of triploid grapes by in ovulo embryo culture. Vitis 37:113-117. 